\title{
UNA FUENTE «CASI» PERDIDA PARA LA HISTORIA DE LA CASTILLA MEDIEVAL. NOTAS EN TORNO AL BECERRO DE SAN PEDRO DE ARLANZA
}

por

\author{
JULIO ESCALONA MONGE \\ Instituto de Historia, CSIC
}

Pilar AzCárate Aguilar-Amat

Instituto de Historia, CSIC
RESUMEN: El cartulario conocido como Becerro de San Pedro de Arlanza es un códice del siglo $X I I$ que recogía los principales documentos del archivo monástico entre comienzos del siglo X y mediados del XII. El códice desapareció durante la Guerra Civil (1936- 1939), por lo cual sólo puede en la actualidad ser conocido gracias a la publicación de sus contenidos entre los fondos arlantinos editados por Luciano Serrano en 1925. Un análisis exhaustivo de los dispersos datos proporcionados por Serrano permite arrojar cierta luz sobre su proceso de redacción y sobre el papel que desempeñó en la formación del corpus documental de San Pedro de Arlanza.

Palabras clave: Castilla. Edad Media. Fuentes. Cartularios. Documentos.

ABSTRACT: The cartulary commonly known as Becerro de San Pedro de Arlanza is a twelfthcentury codex recording the main documents of the monastery's archive from the early tenth to the mid-twelfth century. The codex was lost during the 1936-39 Spanish Civil War, so its contents are only known thanks to Luciano Serrano's 1925 publication of the Arlanza collection. Exhaustive analysis of the data provided by bim sheds some light upon the making of the cartulary and its role in the formation of the Arlanza documentary collection.

KEY WORDS: Castile. Middle Ages. Sources. Cartularies. Documents. 

mismo tiempo editor y albacea del Becerro.

Desde el siglo XII el monasterio burgalés de San Pedro de Arlanza contaba entre sus colecciones documentales y bibliográficas con un cartulario en el que se copiaron la mayor parte de los documentos del archivo monástico comprendidos entre comienzos del siglo X y mediados del XII. A diferencia de otros códices arlantinos, que fueron enajenados en uno u otro momento, el Becerro parece haber permanecido continuadamente en el monasterio hasta la dispersión de sus fondos tras la desamortización. La colección documental de Arlanza fue tremendamente castigada en ese período y debe asumirse la pérdida o destrucción de la mayor parte de su riqueza documental y bibliográfica ${ }^{1}$. Sin embargo, el Becerro no pereció, sino que fue a parar a manos de un chamarilero de un pueblo cercano, de las cuales lo rescató el bibliófilo Francisco de Zabálburu. No se conoce a ciencia cierta la fecha de esta adquisición, pero es seguro que al menos desde1896 el códice ya formaba parte de la Biblioteca de los Condes de Heredia-Spínola (hoy Biblioteca Zabálburu), ubicada en Madrid. Allí fue consultado por Ramón Menéndez Pidal cuando preparaba su obra sobre la Leyenda de los Infantes de Lara y allí lo estudió a fondo el Padre Luciano Serrano con vistas a la publicación de la colección documental de Arlanza, de la cual el Becerro es parte fundamental. Por desgracia, durante la Guerra Civil de 1936-39 el Palacio Heredia-Spínola quedó desocupado y expuesto a toda clase de expolios de piezas valiosas, entre ellas el Becerro de Arlanza, que - a diferencia del Becerro Gótico de Cardeña ${ }^{2}$ - desapareció sin que hasta hoy haya sido posible dar con su paradero, si es que no fue destruido definitivamente. Con ello, el medievalismo castellano perdió, quizá para siempre, una de sus fuentes señeras y desde entonces los especialistas han tenido que limitarse a los datos proporcionados por Serrano.

Es muy poco lo que se sabe sobre la apariencia externa y las características materiales del Becerro 3 . Sólo conocemos dos autores modernos que hayan

\footnotetext{
1 Según noticia del Padre Liciniano Sáez, monje de Santo Domingo de Silos (1737-1809), transmitida por Serrano, los documentos conservados en el archivo arlantino a fines del siglo XVIII pasaban de novecientos: SeRrano, Luciano: Cartulario de San Pedro de Arlanza, antiguo monasterio benedictino, Madrid, 1925, p. vii (en adelante $=$ SERRANO, Arlanza). En la actualidad un recuento optimista no pasaría de 450. Sobre el P. Sáez, ver MATÉ, Lorenzo: «El Padre Liciniano Sáez, archivero de la Cámara de Comptos Reales", Príncipe de Viana, 150-151 (1978), pp. 93-110.

2 También perteneciente a la Biblioteca Zabálburu, y editado por SERRANO, Luciano: Becerro Gótico de Cardeña, Valladolid, 1910 y recientemente por MARTíneZ DíEZ, Gonzalo: Colección Diplomática de San Pedro de Cardeña, Burgos, 1997.

3 La Biblioteca Zabálburu, donde tenía la signatura 11/135, aún conserva una escueta ficha descriptiva con algunos datos básicos, que transcribimos: «ARLANZA (Mon ${ }^{\circ}$ de S. Pedro de): Libro Becerro del Monasterio de Arlanza (Burgos) desde la Era 950 basta la de 1194. MS. De principios del so
} 
hecho alusión a él con cierto detalle: Menéndez $\mathrm{Pidal}^{4}$, y el propio Serrano, quien proporciona la descripción más completa disponible hoy día 5 . Esta es, aparentemente, toda la información de que dispone el especialista moderno para hacerse una idea de cómo pudo ser el Becerro. Por desgracia, carecemos de muchos datos fundamentales. Nada sabemos sobre la decoración y encuadernación del códice. Ignoramos si se trataba de un conjunto unitario o era resultado de coser juntos varios fragmentos; nada sabemos sobre el tipo o el número de cuadernos que lo formaban, ni sobre el sistema de ordenación empleado ni sobre las dimensiones y formato del códice; tampoco conocemos cuál era la preparación previa de las páginas, ni el picado o pautado, ni si la escritura se disponía a línea tirada o, como ocurre en el Becerro de Cardeña, en columnas. Sí sabemos, en cambio, que los documentos iban precedidos de rúbricas, como en el Becerro de Cardeña, aunque Serrano sólo las transcribe en casos puntuales. Tampoco hay apenas pistas sobre notas marginales, correcciones - aunque sabemos que las tenía - o posibles adiciones. Mucho más importante: carecemos totalmente de datos sobre el o los escribas que intervinieron, si hubo una o varias manos, etc., lo que es crucial a la hora de plantear el proceso de redacción... La lista de problemas sería interminable.

Dicho esto, podría pensarse que carece de sentido estudiar de manera monográfica la estructura y génesis de una fuente desaparecida, o que su interés es el de una mera erudición, preocupada por dejar constancia de un testimonio del pasado que ya no podemos ver. Sin embargo, el Becerro de Arlanza, -indirectamente a través de su edición por Serrano- constituye un material frecuentísimamente manejado por los especialistas, y no es en absoluto inapropiado formularse preguntas acerca de la fuente en sí misma, de las circunstancias de su génesis y de los condicionantes de partida que deben ser tenidos en cuenta para su mejor aprovechamiento.

Pensamos que esta preocupación por la fuente está ganando rápidamente el interés de los medievalistas en los tiempos más recientes, mucho más allá del terreno de estudio específico de los especialistas en diplomática. De hecho, es este un terreno especialmente descuidado, ya que tradicionalmente se ha tendido a valorar y criticar la carga de intencionalidad y los condicionamientos heurísticos de materiales narrativos, como crónicas o hagiografías, o iconográfi-

XIII de 98 fol. en $4^{\circ}$, desencuadernado, con acotaciones y enmiendas en los márgenes, forrado en pergamino. Al final lleva un indice en papel, letra del siglo XVII».

4 MENÉndez PIDAL, Ramón: La Leyenda de los Infantes de Lara, $3^{\text {a }}$ ed. aumentada en Obras Completas de R. Menéndez Pidal, I, Madrid, 1971, pp. 447-448 (e. o. 1896).

5 Serrano, Arlanza, p. ix: «Becerro de Arlanza, que se guarda en la Biblioteca de los excelentísimos Condes de Heredia-Spínola, en la cual lleva la signatura de 11,135 ( $\mathrm{Arm}$. 11, $n^{\circ} 135$ ). Está escrito en pergamino, de letra minúscula francesa; sus dimensiones son 0,28 de alto por 0,20 de ancho. La letra $g$ tiene siempre la forma usual en el abecedario visigótico. Sus caracteres paleográficos denotan haber sido escrito este becerro en el último tercio del siglo XII: el documento más moderno de los en el contenidos lleva la fecha de 1156». 
cos, y, sin embargo, los historiadores raramente se lo plantean cuando se trata de fuentes documentales, más allá del tradicional diagnóstico diplomático sobre su falsedad o autenticidad - $\mathrm{y}$ a veces, ni siquiera eso-.

Que las fuentes diplomáticas componen un registro textual muy sutil y difícil de escudriñar, es algo sabido desde antiguo. También lo es que una parte sustancial del volumen de documentación medieval disponible para el historiador no procede de los documentos originales, sino de su recopilación en cartularios, un 'género' heurístico peculiar, y al que se suele dedicar mucha menos reflexión de la que merece. Quizá no sea una casualidad que uno de los frentes de la renovación metodológica arriba apuntada gire precisamente en torno a los códices diplomáticos, auténtico filón del que proceden muchos de nuestros diplomas, pero tremendamente desconocidos como tales obras ${ }^{6}$. El ejemplo que estudiamos en este trabajo entra de lleno en esta problemática.

Dadas las peculiares condiciones de partida - ausencia del códice - trabajaremos en cuatro etapas: en primer lugar, trataremos de establecer qué documentos formaron parte de él, y cómo se organizaban dentro del mismo; en segundo lugar, intentaremos determinar cuáles fueron las etapas de su elaboración; seguidamente nos planteamos qué tipo de estructura archivística subyace al método de compilación y, para terminar, ofreceremos algunas conclusiones sobre las implicaciones que todo ello tiene para la comprensión de este tipo de fuentes y para el uso que los historiadores les dan.

\section{IDENTIFICACIÓN Y ORDENACIÓN DE LOS DOCUMENTOS DEL BECERRO.}

\section{Identificación de los documentos}

En vista de que la ausencia del códice no puede ser resuelta de momento, y no parece que lo vaya a ser en el futuro inmediato, debemos limitarnos a la información proporcionada por los documentos en sí, tal y como los transcribió Serrano. Carecemos de las rúbricas y de las referencias de folio, pero disponemos de los números de orden de los documentos dentro del cartulario y es con ello que debemos empezar a trabajar ${ }^{7}$.

\footnotetext{
6 Ver, por ejemplo, la primera sección de artículos de GuYOTJEANNIN, Olivier; MORELle, Laurent; PARISSE, Michel, comps.: Les cartulaires, Paris, 1993, dedicada a Les cartularies dans l'bistoire de l'ecrit. También algunas observaciones interesantes sobre las asunciones implícitas en la clasificación moderna de obras por géneros en UGÉ, Karine. "Creating a Usable Past in the Tenth Century: Folcuin's 'Gesta' and the crises at Saint-Bertin", Studi Medievali, 37, fasc. II (1996), pp. 887-903.

7 Por brevedad, citamos los documentos de la publicación de Serrano como SPA (San Pedro de Arlanza), seguido del número del documento que él les asigna en su edición (por ejemplo, SPA25); los textos del Becerro se citan como BA (Becerro de Arlanza), seguido del número de orden original en el Becerro (por ejemplo, BA5). En uno y otro caso se indica a continuación y sólo si es necesario, el año de la data. Ver la tabla de equivalencias al final del trabajo.
}

Hispania, LXI/2, núm. 208 (2001) 449-474 
Tabla 1. Piezas documentales en el Becerro de Arlanza.

\begin{tabular}{|c|c|c|}
\hline \multicolumn{2}{|c|}{ A) 97 documentos del Becerro, propiamente dichos: } & $\mathrm{n}^{\text {os }} 1-97$ \\
\hline \multicolumn{3}{|c|}{ De ellos: } \\
\hline & Faltan en la numeración de Serrano & $\mathrm{n}^{\mathrm{os}} 26$ y 39 \\
\hline & Está repetido (= BA39) & $\mathrm{n}^{0} 35$ \\
\hline \multicolumn{3}{|l|}{ A ellos: } \\
\hline & $\begin{array}{l}\text { Hay que añadir un documento (SPA,54), que carece de referen- } \\
\text { cia, pero seguramente procede del Becerro (=BA26) }\end{array}$ & 1 \\
\hline \multicolumn{2}{|c|}{$\begin{array}{l}\text { B) Documentos (2) y noticias (1) incorporados al Becerro a partir del } \\
\text { siglo XIII: }\end{array}$} & 3 \\
\hline \multicolumn{3}{|c|}{ De ellas: } \\
\hline & 2 documentos del s. XIII añadidos al Folio 1 anverso (BAa y BAb) & 2 \\
\hline & 1 noticia añadida al último folio en el s. XIII (BAc) & 1 \\
\hline \multicolumn{2}{|r|}{$\mathrm{Cl}_{\mathrm{r}} \mathrm{r}$} & 100 piezas \\
\hline
\end{tabular}

En primer lugar, es necesario corregir algunos errores de Serrano. El primero, muy evidente, es BA176 (=SPA91), número imposible porque el Becerro sólo tenía 97 entradas, y que debe corresponder en realidad a BA76 que, efectivamente, falta en la numeración. Solventado este detalle menor, quedan tres problemas: a) BA35 está repetido; b) SPA54, del que Serrano no cita procedencia, por su aspecto y contenido parece provenir del Becerro; c) quedan vacíos en la secuencia del editor los puestos BA26 y BA39.

El verdadero $\mathrm{n}^{\circ} 35$ debe corresponder a SPA74 (1069), una donación de bienes en Tardajos, Ranedo, Mojina, Sandoval y Guzmán, que coincide con el ámbito geográfico de BA33, BA34, BA36 y BA37. El otro documento numerado como 35 (SPA22, año 981) es un testamento en favor de San Juan de Tabladillo; en este caso nos inclinamos a pensar que se trata de una errata de escritura del propio Serrano y el número correcto es 39 , fácil de confundir con 35 y que falta en la numeración. Pensamos que estas dos correcciones se pueden aceptar con un grado muy alto de confianza.

Más especulativa es la siguiente: SPA54 podría ser identificado con el ausente BA26 porque su contenido - divisas donadas a Arlanza en el alfoz de Lara- encaja con el contexto geográfico y temático de los correlativos BA24, BA25 y BA27. Esta corrección tiene un carácter mucho más hipotético, pero es lógica y, junto con las anteriores, resuelve el problema de los espacios en blanco de forma convincente. Dándolas por buenas, tendríamos completa la lista de documentos del Becerro desde el 1 al 97. A ellos hay que sumar tres piezas más: dos cartas (que denominamos $\mathrm{BAa}$ y $\mathrm{BAb}$ ) y una mera noticia sin datación (BAc), que fueron añadidos tardíamente al comienzo y al final del códice aprovechando espacios en blanco. 
Resulta, por tanto, que el Becerro de Arlanza contenía, que se pueda saber hoy por hoy, un total de 100 piezas documentales (ver Tabla 1).

\section{Ordenación de los documentos}

A diferencia de su edición del Becerro de Cardeña, que sigue la estructura interna del cartulario, Serrano publica los documentos del Becerro de Arlanza en orden cronológico, mezclados con el resto de la documentación arlantina. Sin embargo, la numeración interna del Becerro permite determinar la ordenación de los textos en el códice y compararlo con sus dataciones (Ver Figura 2)8. Al hacerlo se comprueba que: a) en la mayor parte del texto el orden cronológico brilla por su ausencia; b) si dejamos a un lado las adiciones al comienzo y final, el rango cronológico va desde 912 a 1156.

\section{RELACIÓN ENTRE EL BECERRO Y LA COLECCIÓN DOCUMENTAL DE ARLANZA.}

\section{Documentación procedente de fondos diferentes del arlantino}

Dentro del rango 912-1156, no todos los documentos del Becerro tienen a Arlanza por destinatario. Existe un pequeño conjunto de trece cartas dirigidas a otras instituciones, a cuyos archivos pertenecían originalmente y que se incorporaron al arlantino al ser agregadas dichas casas a la abadía de San Pedro, por lo que la fecha post-quem para su entrada en el archivo de Arlanza es la de la agregación del monasterio correspondiente. En la mayor parte de los casos es fácil establecer la conexión.

La Tabla 2 muestra este grupo de documentos, precisando el momento de su incorporación a Arlanza y, cosa importante, si se presentan en el Becerro de manera correlativa con otros documentos del mismo origen o lo hacen de manera inconexa ${ }^{9}$. Como era de esperar, se comprueba que todas las fechas de

\footnotetext{
8 Como ya advirtiera en su día Serrano, las dataciones de los documentos del Becerro, especialmente los de los siglos X y XI, contienen numerosos errores debidos unas veces a defectos de copia y otras a ser simples falsificaciones, de las que los fondos de Arlanza contienen un gran número. Esta es una cuestión demasiado compleja para abordarla aquí sistemáticamente, por lo que prescindimos de este tipo de consideraciones y, salvo casos concretos, tomamos las dataciones dadas por Serrano. Algunas consideraciones de interés sobre dataciones erróneas en documentos regios de Fernando I se pueden ver en BLANCO LOZANO, Pilar: Colección diplomática de Fernando I, León, 1987, passim (en adelante $=$ Fernando $I$ ). Para un análisis más minucioso de las dataciones, nos remitimos a sendos trabajos que se realizan actualmente en el Instituto de Historia del CSIC y el Departamento de Biblioteconomía y Documentación de la Universidad Carlos III de Madrid: una nueva edición de los fondos arlantinos; y la monografía Falsear el pasado, construir el presente: El monasterio de San Pedro de Arlanza y los fueros apócrifos de Lara y Salas (Burgos), que se encuentra en avanzado estado de elaboración.

9 Cabe hacer, sin embargo, alguna precisión:
} 
incorporación de fondos a Arlanza quedan dentro del rango 912-1156, cubierto por el Becerro, incluso en casos en que la agregación a Arlanza no se trasladó al Becerro (cuestión de la que nos ocuparemos posteriormente). Por otra parte, la impresión general es que el agrupamiento de documentos por temas es mucho más consistente al comienzo del Becerro que al final.

Tabla 2. Documentación no arlantina incluida en el Becerro.

\begin{tabular}{|l|l|l|l|l|c|}
\hline BECERRo & SERRANO & AÑo & ORIGEN & INCORP. A ARLANZA & $\begin{array}{c}\text { CORRE- } \\
\text { LATIVO? }\end{array}$ \\
\hline BA5 & SPA6 & 929 & San Millán de Belbimbre & Fernando I 1048 & Sí \\
\hline BA9 & SPA42 & 1044 & Villariezo & Fernando I 1048 & Sí \\
\hline BA15 & SPA5 & 929 & Santa María de Lara & $\begin{array}{l}\text { Urraca 1038 / Fernan- } \\
\text { do I 1039 }\end{array}$ & Sí \\
\hline BA20 & SPA8 & 930 & San Mamés de Ura & Fernando I 1042 & Sí \\
\hline BA36 & SPA14 & 937 & San Andrés de Boada & Sancho II 1069 & No \\
\hline BA39 & SPA22 & 981 & San Juan de Tabladillo & Fernando I 1041 & No \\
\hline BA46 & SPA4 & 924 & San Juan de Tabladillo & Fernando I 1041 & No \\
\hline BA47 & SPA49 & 1048 & Santa Cruz de Baños & $?$ & No \\
\hline BA49 & SPA19 & 1058 & San Juan de Canales & Fernando I 1062 & No \\
\hline BA52 & SPA80 & 1076 & Cela Quesón & Fernando I 1042 (?) & No \\
\hline BA62 & SPA16 & 942 & San Pedro de Berlangas & ? & No \\
\hline BA70 & SPA17 & 964 & San Andrés de Boada & Sancho II 1069 & No \\
\hline BA95 & SPA27 & 1032 & San Martín de Villaquirán & Alfonso VII 1154 & No \\
\hline
\end{tabular}

- BA5 (dotación de San Millán de Belbimbre) figura en el becerro correlativo con dos copias de la agregación de este monasterio a Arlanza por Fernando I en 1048 (BA3 y BA4), pero BA5 es una falsificación elaborada a partir de de BA15 (ver ZABALZA DuQue, Manuel: Colección Diplomática de los Condes de Castilla, Salamanca, 1998, pp. 132 ss.).

- BA9 (donación del concejo de Villariezo al abad Jimeno). No se nombra el monasterio, pero debe de ser uno de los dos de esa localidad agregados a Arlanza por Fernando I en 1048 (BA10), que figura contiguo en el Becerro.

- BA20, (San Mamés de Ura) es un texto complejo, que amalgama un pacto monástico con una donación de Fernán González (ZaBALZA, Condes de Castilla, pp. 150 ss.).

- BA39 y BA46 (San Juan de Tabladillo). La agregación de San Juan a Arlanza por Fernando I en 1041 (SPA34) falta en el Becerro (ver más adelante).

- BA52 (Cela Quesón). Su ubicación no tiene relación con la probable agregación por Fernando I en 1042 (ver las precisiones que se hacen más adelante).

- BA62 una donación de derechos en Salinas de Añana efectuada por Fernán González en favor de un monasterio que se viene identificando con San Pedro de Berlangas. La única lógica de su inclusión en el Becerro es que estos derechos hubiesen pasado a disfrute de Arlanza, pero no hay constancia documental de este paso.

- BA95 (San Martín de Villaquirán). Su agregación a Arlanza por Alfonso VII en 1154 (SPA111) falta en el Becerro (ver más adelante). 
Documentación arlantina no incluida en el Becerro.

Una vez establecida la sucesión de diplomas y - cuando ello es posiblelas razones de la inclusión de documentos de fondos ajenos, es necesario contrastar este material con la documentación arlantina del mismo período que, por una u otra razón, no fue incluida en el Becerro. La Figura 1 muestra la documentación de Arlanza anterior a 1200 publicada por Serrano pero no representada en el Becerro.

Figura 1. Documentación arlantina no incluida en el Becerro.

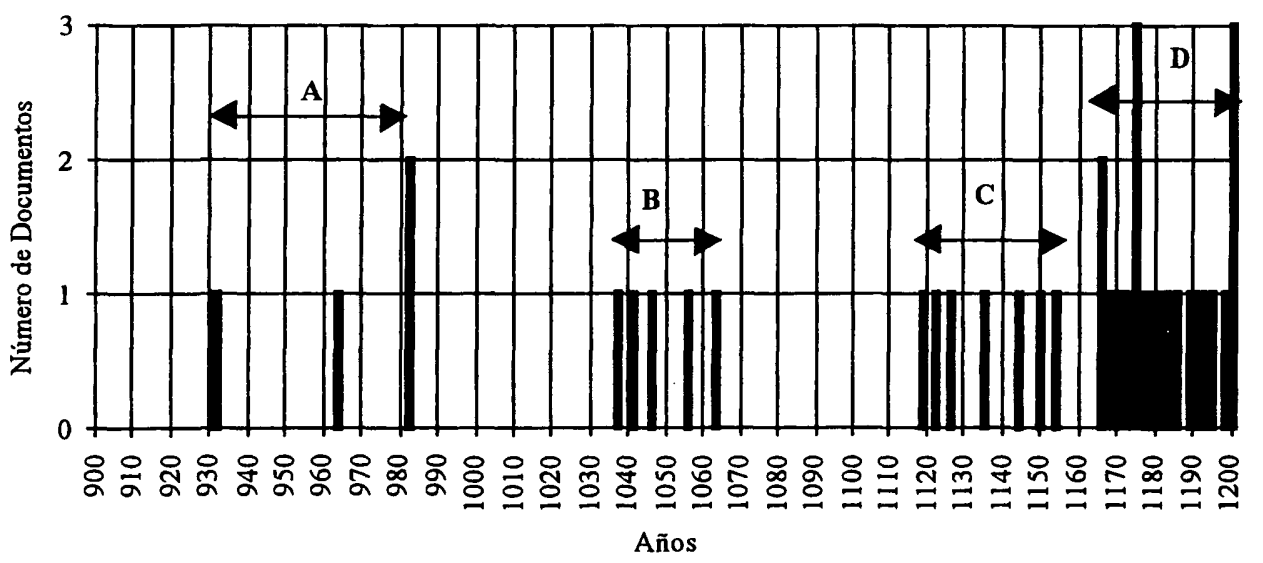

El primer fenómeno que salta a la vista es que el número de documentos no incluidos se dispara desde 1166 y se mantiene en lo sucesivo (grupo D de la Figura 1). A partir de esa fecha, y a lo largo del reinado de Alfonso VIII, Arlanza obtuvo muchos diplomas de contenido muy relevante para el monasterio, pero ninguno de ellos se copió en el cartulario. Esto demuestra que, con todas sus lagunas, el Becerro cubría los fondos documentales monásticos hasta 1156 - fecha del último documento- de manera bastante exhaustiva, y que, aunque ocasionalmente se le añadiese alguna otra carta, hacia 1160 era ya una obra rematada.

Por lo que respecta al resto de las omisiones —un total de quince-, cabe señalar tres bloques bien diferenciados. El primero (grupo A) comprende cinco documentos datados entre los años 931 y 982. Dos de ellos - SPA12 (año 932) y SPA18 (año 965) - es lógico que no figuren en el Becerro, porque no parecen haber pertenecido a los fondos de $\operatorname{Arlanza}^{10}$. Por su parte, SPA9 (año

10 El primero es la emancipación de San Cristóbal de Vallegimeno, un texto que se ha transmitido a través de una sola copia en letra visigoda en un cuadernillo de pergamino, con la datación 
931), el pacto monástico de San Juan de Tabladillo, sí tiene relación con Arlanza, pero, al igual que la agregación de San Juan a Arlanza por Fernando I, no fue copiado en el Becerro (sobre esto ver más adelante).

La ausencia de los dos textos de 982 no es tan fácilmente explicable. Se trata de sendas traditiones en Contreras y Jaramillo efectuadas por presbíteros de la comarca de Lara directamente en favor del monasterio de Arlanza, cuyos originales no se conservan, pero probablemente pertenecieron al archivo monástico desde el momento de su redacción ${ }^{11}$. A falta de mejores pistas, su ausencia del Becerro sólo puede ser explicada por un error o una selección consciente de los compiladores.

El segundo grupo (grupo B) lo forman cinco documentos del reinado de Fernando I (SPA29, 34, 47, 57 y 65). Podemos explicar fácilmente la ausencia de SPA $57^{12}$ y SPA $47^{13}$, pero los tres restantes merecerán una discusión detallada. SPA65 (año 1063) es una carta de sometimiento del monasterio de San Miguel de Osma a Arlanza, de la cual se conserva el original en el Archivo Histórico Nacional ${ }^{14}$. Los derechos sobre San Miguel de Osma forman parte de un bloque de intereses de Arlanza que dieron lugar a una larga serie de pleitos con el obispado de Osma a partir de la definitiva restauración de sus límites dioce-

errónea de 924. Tanto la data como el contenido son sospechosos. Las conexiones de uno de los otorgantes con el poema de Fernán González y del otro con la Leyenda de los Infantes de Salas sugieren que se trata de una falsificación del siglo XII o posterior incorporada tardíamente a los fondos de Arlanza. (Sobre esta cuestión, véase EsCALONA, Julio: "Épica, crónicas y genealogías. En torno a la historicidad de la Leyenda de los Infantes de Lara», Cabiers de Linguistique Hispanique Médiévale, 23 (2000), pp. 113-176). En cuanto al segundo, es un reconocimiento de propiedades en Camporredondo que no parece haber pertenecido a los fondos de Arlanza, sino a los de Oña (SERRANO, Arlanza, p. 49). Ignoramos la razón por la que Serrano lo incluyó en su obra.

11 No son diplomáticamente sospechosos. Los conocemos a través de las - generalmente fiables- versiones copiadas en el siglo XVIII en el ms. 10 del Archivo de Santo Domingo de Silos por el P. Sáez a partir de los originales que se conservaban en Arlanza. Una posible explicación de su ausencia del Becerro es que se trata de diplomas otorgados por personajes de mediana extracción social, mientras que el resto de los documentos del siglo $\mathrm{X}$ son invariablemente diplomas condales $\mathrm{u}$ otorgados por aristóctatas, con la excepción de BA39 (año 981), que en todo se asemeja a los casos que nos ocupan y sí fue en cambio copiado en el Becerro. Sin embargo el destinatario de este último no es Arlanza, sino San Juan de Tabladillo.

12 SPA57 (año 1056) es una permuta entre los monasterios de Arlanza y Oña; el Becerro $(B A 41=$ SPA56) recoge la versión otorgada por Oña en favor de Arlanza, mientras que la inclusión del texto inverso, otorgado en favor de Oña, es una decisión editorial de Serrano independiente de la colección arlantina.

13 Parece fácil explicar la ausencia de SPA47 (una donación por Fernando I de propiedades y derechos regios en el alfoz de Lerma), ya que una versión de este texto ligeramente 'retocada' sí se copió en el Becerro (BA22). Dado que SPA47 parece haber permanecido siempre entre los fondos de Arlanza, la conclusión sería que se optó por trasladar al Becerro la version 'mejorada'.

14 AHN, Clero, carpeta 368, $n^{\circ} 6$. 
sanos en 1136. Ignoramos cuándo se inició la querella ${ }^{15}$ y cuál fue su desarro1lo, aunque sabemos que se resolvió cuando en 1195 (SPA129) Arlanza terminó por renunciar a sus pretensiones sobre San Miguel de Osma pro bono pacis et finiendis contentionibus. No está claro en qué medida este pleito pudo influir en que el documento de 1063 se dejase de trasladar al Becerro, pero quizá el caso siguiente pueda arrojar alguna luz.

El monasterio de Cela Quesón constituye un pequeño embrollo, empezando por su denominación. Ubicado en las proximidades de Valdehande, en el alfoz de Clunia, aparece en ocasiones bajo el nombre de Cela Quesón, o semejantes, pero su advocación correcta parece haber sido Santa Marina virgen y San Miguel; sin embargo, en ocasiones se le adjudica la de Santa María, quizá por un comprensible error de copia o transcripción. En cambio, debe ser distinguido de San Juan de Cela, en el alfoz de Muñó, aunque Serrano parece confundirlos, si nos atenemos a que en el índice de su publicación figura una sola entrada para ambos ${ }^{16}$. Contamos con un total de seis documentos sobre este monasterio. Cronológicamente, el más antiguo es precisamente el que falta en el Becerro, SPA29 (1037), por el que Fernando I emancipó y dotó el monasterio de Santa Marina de Cela ${ }^{17}$. Tratándose de un documento propio de Santa Marina, parece lógico que pasase al archivo de Arlanza a raíz de la incorporación de Santa Marina a éste.

Aquí precisamente empiezan los problemas. El Becerro nos ha transmitido nada menos que tres documentos para esta anexión, dos a cargo de Fernando I —BA28 (año 1042) y BA65 (año 1044) - y uno de Alfonso VI: BA29 $\left(\right.$ año1091) ${ }^{18}$. Serrano interpretó esta secuencia como que la donación original

15 Un posible punto de partida puede ser un documento de Sancho III de 1154 por el que donó a la Iglesia de Osma el monasterio de San Miguel de Osma, entre otros bienes: Concedo etiam vobis et confirmo in Oxsoma monasterium sancti Michaelis, cum omnibus bereditatis et pertinenciis suis... (GonZÁleZ, Julio: El Reino de Castilla en la época de Alfonso VIII, Madrid, 1960, t. II, doc. 12). El diploma existe original en el Archivo de la Catedral de Osma. Esto no quiere decir que la disputa empezase a partir de 1154. La propia donación regia puede ser consecuencia de que la disputa estaba ya en marcha.

16 Que se trata de dos monasterios diferentes queda meridianamente claro gracias a la bula de Honorio III de 1217 (SPA129) en que ampara los bienes de Arlanza, dando una entrada separada para cada uno de ellos.

17 No se conserva el original, sino una confirmación por Alfonso X en 1255 (AHN, Clero, Carpeta $370, \mathrm{n}^{\circ}$ 9) que puede haber transmitido mal la fecha. Cfr. BlANCO, Fernando I, pp. 56-59. Serrano regesta este documento como una agregación de Santa Marina a Arlanza (ver SerRANO, Arlanza, p. 63), cosa que el texto no corróbora, porque se trata de una carta dirigida al abad de Santa Marina y contiene una emancipación con un formulario standard. Este detalle también parece haber escapado a Blanco, quien lo trata como un documento dirigido a Arlanza (BLANCO, Fernando $I$, pp. 76). No hay razón alguna para considerar al abad Vicente, destinatario del documento, como abad de Arlanza, aunque eso proponga ZARAGOZA PASCUAL, Ernesto: «Abadologio del monasterio de San Pedro de Arlanza (siglos X-XIX)», Boletín de la Institución Fernán González, 210 (1995), pp. 85-109, en p. 89.

18 Sobre la data ver más adelante, n. 20.

Hispania, LXI/2, núm. 208 (2001) 449-474 
era el documento de 1037 , por lo que todas las demás serían ratificaciones, cosa que los textos no corroboran. Debe notarse que tanto BA28 como BA65 tienen problemas de autenticidad ${ }^{19}$. BA28 lleva una data errónea y BA65 otro tanto, pero este además presenta un formulario caótico, con fórmulas frecuentemente truncadas y abundantes incoherencias gramaticales que hacen pensar en una amalgama de textos o una falsificación poco habilidosa ${ }^{20}$. Por otra parte, en 1076 (BA52) un personaje noble efectúa una traditio directamente en favor de Cela Quesón, sin mención alguna de su dependencia de Arlanza - cosa no totalmente insólita- y años después (1091) Alfonso VI de nuevo entrega el monasterio de Cela a Arlanza ${ }^{21}$. Dejando a un lado BA65, que parece claramente falso, no es fácil decidir si la anexión auténtica es la de Fernando I o la de Alfonso VI o ambas, pero quizá sea un dato relevante que los redactores del Becerro las colocaron yuxtapuestas ( $\mathrm{n}^{\circ} \mathrm{s} 28$ y 29), mientras que los otros diplomas relativos a Cela Quesón ocupan los lugares 52 y 65, respectivamente. Quizá sea posible entender los textos de Fernando I y Alfonso VI como una donación y una ratificación, mientras que BA65 sería una burda falsificación.

La cosa se complica porque al menos una de esas cartas estuvo enajenada del archivo arlantino durante algún tiempo. En 1147 se efectuó una convenientia entre Arlanza y el Obispado de Osma para zanjar una querella en torno al monasterio de Cela Quesón. En ese texto se nos relata, de manera muy eufemística, que el obispo Beltrán de Osma (1128-1140) había tenido en su poder - sin que sepamos por qué medios- el título de posesión de Cela Quesón, documento que el monasterio recuperó precisamente a raíz de este acuerdo efectuado con el obispo Esteban, sucesor de Beltrán ${ }^{22}$. Hay dos puntos oscuros que no podemos resolver: a) no sabemos desde cuándo estaba la carta en poder de Osma, ya que pudo ocurrir en cualquier momento entre 1128 - e incluso anteriormente - y 1140 ; b) tampoco sabemos cuál era esa carta que estuvo fuera del archivo monástico durante esos años. Lo que sí sabemos es que hasta 1147 — más tarde, si el acuerdo se puso en práctica 'lentamente'- no volvió a los anaqueles de Arlanza. En todo caso parece que a mediados del siglo XIII los monjes de Arlanza consideraban que la pieza más valiosa de todas estas era la dotación de 1037, ausente del Becerro, ya que es la única que presentaron a Alfonso X para su confirmación.

\footnotetext{
19 Ver BLANCO, Fernando I, docs. 18 y 24.

20 En general, la impresión es que se trata de una amalgama de los dos anteriores, entre otras cosas porque aquí aparece el abad Vicente como abad de Arlanza.

21 La data del Becerro es 1081 , pero ha sido corregida a 1091, basándose en la cronología de los confirmantes, por Gambra, Andrés, Alfonso VI. Cancillería, Curia e Imperio, León, 1998, v. II, pp. 294 ss.

22 SPA103 (1147): Sicut igitur sepe multis intervinientibus causis solet contingere privilegia possessionis ad ius aliene ecclesie pertinentis in potestatem alicuius prelati devenire, sic accidit Bretannum, pie memorie oxomensem episcopum, privilegium monasterii quod apellatur Cella de meo Quesson quod ecclesia beati Petri diu iureque possederat, inter privilegia possessionum ecclesie cui preerat forte reperisse...
} 
Para terminar, SPA34 (1041), agregación por Fernando I a Arlanza del monasterio de San Juan de Tabladillo, también falta en el Becerro. A raíz de esta donación debieron de entrar a formar parte de los fondos arlantinos los restantes documentos de diferentes épocas que tienen por destinatario a San Juan en vez de Arlanza. El hecho de que algunos de ellos fueran copiados en el Becerro indica que la agregación había sido ya efectiva, por lo que la razón para la ausencia del documento principal debe ser otra. Carecemos del original de SPA34 y tampoco parece que se encontrase entre los fondos de Arlanza en época moderna, ya que todas las copias tardías que se nos han transmitido proceden de su confirmación por Alfonso X en 125523. Más aún, su texto reproduce de forma mimética la mayor parte del documento de emancipación del monasterio de San Juan otorgado por Rodrigo Díaz — SPA4 (año 924)—, que sí se trasladó al cartulario (BA46), como también se copió otra donación particular efectuada en 981 por un presbítero en favor de San Juan (SPA22 = BA39) ${ }^{24}$. De nuevo la explicación parece ser una disputa. En 1175 - pero no sabemos desde cuándo- San Pedro de Arlanza y Santo Domingo de Silos estaban enfrentados a causa de los derechos que cada uno tenía en el alfoz de Tabladillo: Arlanza tenía, entre otras propiedades, el monasterio de San Juan y derechos sobre el diezmo de la rentas regias en el alfoz, obtenidos a partir de la donación de Fernando I que nos ocupa. A ello el abad de Silos sólo podía oponer que la reina Urraca y Alfonso VII les habían donado en 1125 el señorío sobre todo el alfoz ${ }^{25}$ y la prescripción de los derechos de Arlanza por cuarenta años de disfrute indisputado (lo que de nuevo nos lleva a los años 30 del siglo XII, poco después del paso de la jurisdicción de Tabladillo a Silos). Sin embargo, Arlanza pudo obtener al menos una compensación económica gracias a presentar el instrumento público por el que el rey Fernando I les donó el monasterio ${ }^{26}$. Por lo tanto, en 1175 Arlanza poseía el documento de donación de

23 Archivo del Monasterio de Santo Domingo de Silos, E. LII, 1.

24 En cambio, no se copió el pacto monástico de 931 (SPA9). Serrano publicó este texto a partir de la edición parcial contenida en la Escuela Paleographica de Merino (lámina 77). Tampoco fueron copiados en el Becerro otros dos pactos monásticos de San Juan de Tabladillo, de los años 954 y 981 , de los que Serrano nada dice, pero que pertenecieron a los fondos de arlanza y se conocen en regesta a través de un índice documental de mediados del XVIII: Biblioteca Zabálburu, Indice de Arlanza, II, D-406 y II, D-406v.

25 Vivancos, M. C. (1988): Documentación del monasterio de Santo Domingo de Silos (954-1254), Burgos, docs. 37 y 38 (en adelante $=$ VIVANCOS, silos).

26 In causa que vertebatur inter Michaelem, abbatem Sancti Petri de Aslança, et Paschasium, abbate Sancti Dominici, in presentia domini Celebruni, toletani archiepiscopi et Hispaniarum primatis, duas sernas que sunt circa villam que dicitur Cocos, una quarum dicitur serna de Enebral, et quoddam molendinum quod est inter utramque sernam edificatum, et decimas de sernis regalibus de Tablatello cum uno excusato, similiter decimas de sernis regalibus de Orta cum uno excusato, et ecclesiam Sancte Eugenie cum omnibus hereditatibus et terminis eius; et ad bec probanda produxit abbas Sancti Petri instrumentum publicum, in quo continebatur regem Fernandum bone memorie predicta omnia et alia plura donasse ecclesie Beati Petri. Abbas vero Sancti Dominici opposuit ei prescriptionem quadraginta annorum: dicebat enim se predicta

Hispania, LXI/2, núm. 208 (2001) 449-474 
Fernando I, que probablemente es el mismo que se presentó a Alfonso X para su confirmación en 1255. Parece lógico que la convenientia de 1175 entre los dos monasterios - a diferencia de la de 1147 con Osma- no fuese copiada en el cartulario, puesto que es posterior al fin de su redacción hacia $1156^{27}$. Pero ¿por qué no fue copiada la donación de San Juan de Tabladillo por Fernando I y sí lo fueron en cambio otros documentos propios de San Juan? ¿Es posible que el documento estuviese ausente del archivo arlantino por estar siendo utilizado en el proceso de la disputa? Por el momento no podemos dar respuesta a este interrogante, pero el ejemplo de Cela Quesón puede dar alguna pista.

$\mathrm{El}$ tercer grupo de textos ausentes del Becerro (grupo $\mathrm{C}$ ) son siete diplomas de los años 1119 a1154. Cinco de esos casos pueden ser resueltos sin dificultad: los dos documentos relativos al distrito de San Román de Entrepeñas ${ }^{28}$, que entraron tardíamente a formar parte de la colección arlantina, así como otros tres que son sendas decisiones editoriales de Serrano, quien los incorporó aunque no formaban parte de los fondos de Arlanza ${ }^{29}$. Quedan, por una parte, SPA92 (año 1122), un acuerdo de términos que afecta a Santa María de Retortillo, y por otra SPA111, que recoge la donación a Arlanza de los lugares de San Martín de Coitrales y Tabladillo de Lara y la iglesia de S. Martín de Villaquirán por Alfonso VII en $1154^{30}$. La datación de este último documento no parece discutible, sin embargo, debe tenerse en cuenta que el propio texto indica que se cede el monasterio de San Martín de Villaquirán, con todas sus pertenencias, "tal y como figuran en los escritos de dicho monasterio". La única carta de los fondos arlantinos dirigida a San Martín es un documento priva-

omnia que abbas Sancti Petri petebat in pace possedisse quadraginta annis; proponebat separatim boc probare testibus idoneis. Abbas Sancti Petri asseverabat multas intrubciones (sic) ab antecessoribus suis factas, et boc similiter testibus probare paratum se esse dicebat. (VIVANCOS, Silos, doc. 69, año 1175). El original, que formó parte de los fondos de Silos hasta 1792, ya se había perdido cuando Ferotin elaboró su edición de los fondos silenses, por lo que tanto este autor como Vivancos reproducen la transcripción de Berganza, Francisco de: Antigüedades de España, II, Madrid, 1721, pp. 463-465. Para la identificación del texto aludido, ver Vivancos, Silos, p. 99, n. 2.

27 El texto del acuerdo procede de los fondos de Silos, de la misma colección proviene un documento por el que el abad de Arlanza reconoce haber recibido del de Silos la compensación estipulada (VIVANCOS, Silos, doc. 71, 1176).

28 SPA89 (año 1119) y SPA93 (año 1126). Son dos transacciones particulares en favor del mismo personaje, Domingo Bellidez, en la zona de San Román de Entrepeñas.

29 SPA95 es el fuero de Lara otorgado por Alfonso VII en 1135 y del que, por lo que sabemos, no había copia en Arlanza. SPA100 y SPA104 son dos cartas papales obligando a Arlanza a someterse a la autoridad del obispo de Burgos en lo referente a los diezmos. Por razones obvias, estos textos se conservan en los fondos de la Catedral de Burgos, y no entre los de Arlanza.

30 Según Serrano, en el Seminario de Sigüenza se conserva un calco del original que, al parecer estaba escrito en caracteres visigóticos, lo que es poco corriente en un diploma regio de fecha tan tardía (SERRANO, Arlanza, p. 208). El texto fue confirmado por Alfonso X en 10 de febrero de 1255 y poco después Arlanza entregó a Las Huelgas sus bienes en Villaquirán en permuta por otros en el territorio de Lara (LizoAin Garrido, José Manuel: Documentación del Monasterio de Las Huelgas de Burgos (1231-1262), Burgos, 1985, doc. $\mathrm{n}^{\circ}$ 482). 
do de 1032 (BA95), que fue copiado al final del Becerro, en una sección que - como veremos - parece ser un conjunto de adiciones más bien anárquicas. Esto, junto con la ausencia del diploma de anexión de San Martín, sugiere que si la carta fue otorgada en 1154, al menos en ese momento no estaba disponible para ser copiada en el cartulario, o esta tarea se dejó pendiente y no se completó.

En definitiva, el estudio de los textos ausentes del Becerro permite extraer cinco conclusiones:

1) El alto número de diplomas del reinado de Alfonso VIII, ninguno de ellos copiado en el Becerro, corrobora que éste se terminó de redactar entre 1156 y 1166 .

2) Del resto de las omisiones, una gran parte se explica por tratarse de textos que nunca formaron parte de los fondos de Arlanza, pero Serrano decidió incluirlos en su edición.

3) Otras se explican por tratarse de documentos dirigidos a diferentes instituciones que sólo más tardíamente entraron a formar parte - junto con sus archivos- del patrimonio de Arlanza.

4) Un cuarto grupo es debido a que los documentos en cuestión afectaban a intereses que estaban en litigio durante los años en que se redactó el cartulario, por lo que es posible que estuviesen ausentes del monasterio, siendo utilizados en procesos judiciales o a veces incluso enajenados. No cabe descartar la posibilidad de que alguno de ellos se falsificase ad hoc para ser utilizado en esos litigios.

5) Finalmente, hay un conjunto de textos cuya ausencia sólo se explica por descuido o selección consciente de los compiladores, especialmente en el caso de documentos particulares del siglo X, aparentemente no sospechosos, pero que no fueron copiados.

Con estas deducciones podemos plantear a continuación la compartimentación interna del Becerro. Para ello deberemos combinar tres criterios: el orden cronológico de los diplomas, su contenido temático, y los otorgantes y receptores de los mismos.

\section{LA COMPARTIMENTACIÓN INTERNA DEL BECERRO.}

\section{Cronología de los documentos}

El Becerro de Arlanza, como tantos otros cartularios, no se recopiló siguiendo un criterio cronológico, sino temático. Esto se puede comprobar ordenando los documentos según su numeración en el códice y presentando en un gráfico las fechas de cada uno de ellos (Figura 2). 
Figura 2. Becerro de Arlanza. Ordenación y datación de los documentos. Las tres líneas discontinuas verticales indican la proposición de las tres noticias carentes de data.

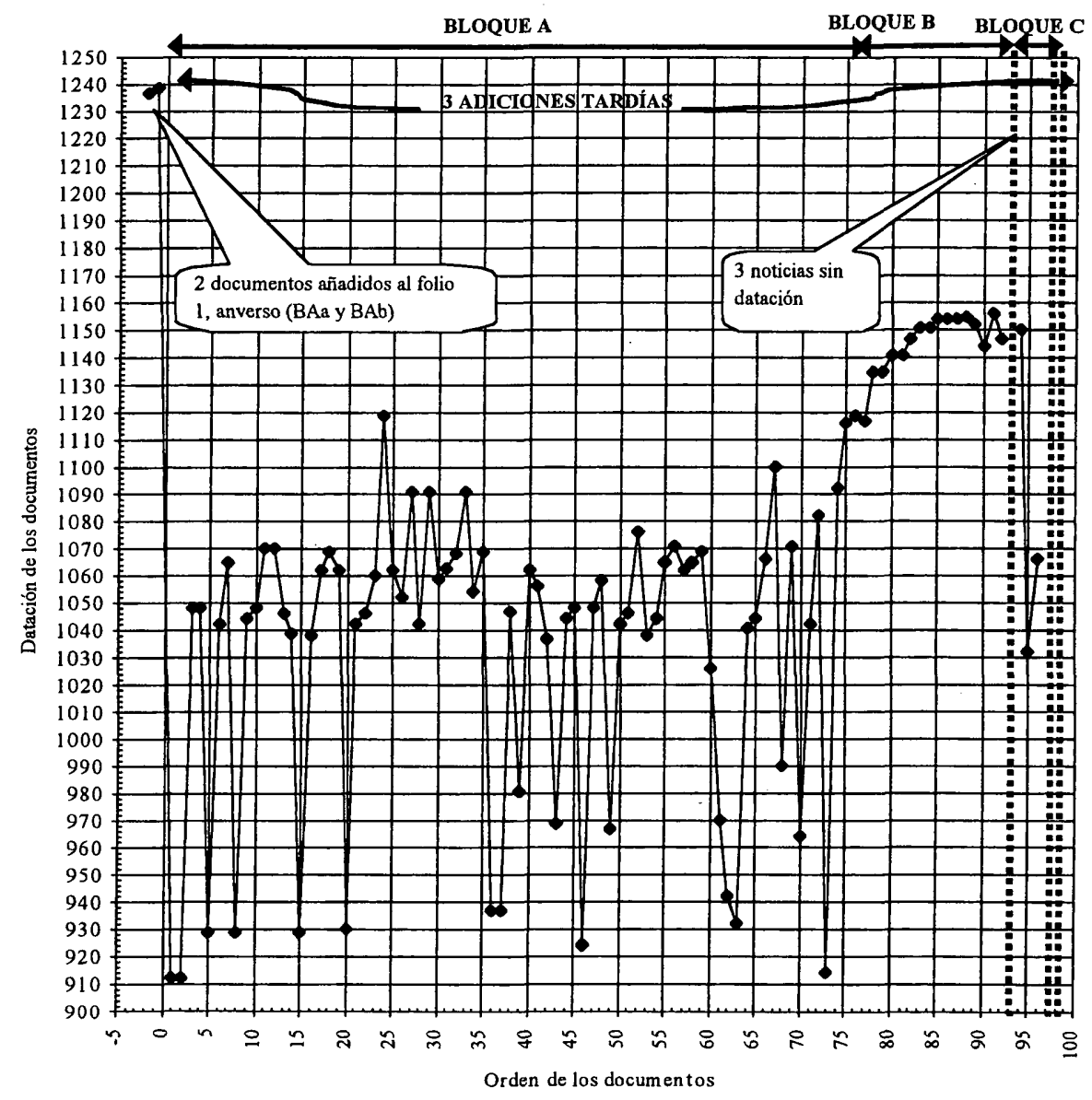

Bloque A: Dejando a un lado los dos documentos BAa y BAb copiados en el folio 1r y la noticia BAc añadida en el último, la distribución de dataciones permite identificar inmediatamente una gran cesura, aparentemente situada en torno al $\mathrm{n}^{\circ} 75$ : hasta $\mathrm{BA} 74$, no parece haber ninguna relación fija entre datación y posición en el Becerro. Constantemente hay saltos y retrocesos: diplomas antiguos suceden a otros más modernos y viceversa. Esta distribución es la típica en los casos en que se organiza la colección por criterios geográficos o temáticos, más que cronológicos (por ejemplo, Becerro de Cardeña). En cambio, desde el $n^{\circ} 75$ se aprecia una progresión casi cronológica. Las dataciones -que oscilan entre 1116 y 1156 - avanzan en orden ascendente, con pequeños desajustes. Esta compartimentación interna sugiere un cambio de criterio 
en la elaboración del Becerro, que debe corresponder a dos etapas de su redacción. ¿Es posible precisar mejor su cronología? El cambio se aprecia en torno al documento BA75, de 1116. A él siguen otros dos textos pertenecientes también al reinado de Urraca (1109-1126), seguidos a su vez de todos los del reinado de Alfonso VII (1126-1157). A primera vista podría situarse la cesura entre el reinado de Alfonso VI y el de Urraca, pero debe repararse en que BA24 es un documento de Urraca, de 1119 , y está colocado muy alejado de los antes citados, en una parte del Becerro en la que el agrupamiento temático predomina. Creemos que esta razón indica claramente que fue en pleno reinado de Urraca o comienzos del de Alfonso VII cuando se elaboró el primer bloque del Becerro, que denominaremos Bloque $A$ y que abarca hasta el documento BA77 inclusive, en vez de hasta BA75. Consideramos, por tanto, el Bloque A formado por los textos 1 a 77 .

Bloque B: A partir de aquí, en el bloque siguiente sí es claro que todos los textos se mueven dentro del reinado de Alfonso VII. Los más antiguos se remontan a $1135^{31}$ y el más reciente a 1156 . Ningún documento dentro de este

31 Es necesario hacer una precisión que afecta a la cronología de todo el bloque. El documento SPA94 (=BA79), datado en 1130, aparece en el becerro después de BA78, datado en 1135. BA79 es una carta por la que Alfonso VII donó a Arlanza el décimo del montazgo del señorío de Lara. El documento ha sido considerado falso por diversos autores (RAssow, Peter: «Die Urkunden Kaiser Alfons VII von Spanien. Eine paleographisch-diplomatische Untersuchung», Archiv für Urkundenforschung, 10/3 (1929), pp. 328-467, en p. 421; ReILly, Bernard F.: «'The Chancery of Alfons VII of León-Castilla: The period 1116-1135 reconsidered», Speculum, 51 (1976), pp. 243-261, en p. 257, nota 87 y LuCas Alvarez, Manuel: Las Cancillerías Reales (1109-1230), León, 1993, pp. 126-127, que lo juzga rehecho a partir de otro de fines del siglo XI). Hay pocas dudas de que se trata de un texto extraño, en el que se entremezclan fórmulas inusuales con elementos de la época. Algunas signaturas parecen pertenecer al siglo XI. En su estado actual, sólo cabe considerarlo como un texto fuertemente retocado o alterado.

Para nuestro interés actual, es más importante la cuestión de la data. Pensamos que hay razones para suponer que la fecha correcta de este texto es 1135 , en vez de 1130 , y ello por varias razones:

- La alteración se explicaría por una sencilla confusión del escriba, al cambiar una $\mathrm{V}$ por una $\mathrm{X}$.

- Con esta corrección cuadra mejor el contexto político. No parece probable una data de 1130. Este año fue crucial en las relaciones entre Alfonso VII y los Lara. El titular del señorío, el conde Pedro González, fue prendido in civitate Palentina — probablemente Palenzuela - en junio de 1130 por el rey, quien, tras conducirle a León, se dirigió contra su hermano Rodrigo González, cuya base eran las Asturias de Santillana: SÁNCHEZ BeLDA, Luis, ed. Chronica Adefonsi Imperatoris, Madrid, 1950, I, 18-22. Estas acciones tuvieron lugar en el norte de las actuales Palencia y Burgos. El único indicio de que el rey pisase la comarca de Lara en ese año sería precisamente el documento arlantino que nos ocupa (Cfr. ReCuero ASTRAY, Manuel, Alfonso VII, Emperador:El Imperio Hispánico en el siglo XII, León, 1979, pp. 208 y ss.).

- En cambio, 1135 parece mucho más probable. En este año, ya muerto Pedro González y retornado su hermano Rodrigo al servicio regio, Alfonso VII emprendió una activa campaña de reorganización de la comarca de Lara, incluyendo la concesión de fueros a la villa de Lara a 3 de mayo de 1135 (SPA95). El 26 de mayo de ese mismo año se coronó Emperador en León y ese mismo día otorgó privilegios a Arlanza (BA78), y fueros al burgo de Santo Domingo de Silos (VIvancos, Silos, 
intervalo aparece en el bloque A. Consideramos, por tanto, el bloque B formado por los diplomas 78 a 92 .

Bloque C: Los últimos documentos presentan un aspecto especialmente informal y desorganizado, que sugiere que el grueso de la obra estaba ya compuesto y se añadieron algunas piezas más con carácter complementario: BA93 es una mera noticia sobre los derechos de pasto de los ganados de Arlanza, sin datación, aunque siguiendo - aparentemente- en orden de escritura a BA92. Podría estar marcando el cierre de dicha fase. BA94 (año 1150), es una donación de aspecto normal, en el rango cronológico del bloque B del Becerro; BA95 y BA96 son una clara intrusión: dos diplomas del siglo XI (años1032 y 1066) relativos al territorio de Castrogeriz ${ }^{32}$; BA97 es una noticia sin datación sobre posesiones de Arlanza en Villasilos, que puede corresponder a finales del siglo XII o comienzos del XIII. Este parece ser el último texto incorporado de una manera correlativa y podría, a su vez, estar marcando el cierre del bloque $C$.

Adiciones tardías: Los tres textos añadidos posteriormente se acomodan como pueden a los espacios disponibles: BAa y BAb, ambos de la década de los 30 del siglo XIII, ocupaban el anverso del primer folio; por desgracia, Serrano no da detalles sobre la letra en que están escritos, por lo que podrían haberse incorporado en ese momento, o quizás mucho más tarde. Finalmente, en el reverso del último folio estaba escrita una noticia sin data (BAc) sobre los derechos de pasto de Arlanza, la cual aprovecha y romancea parcialmente el fuero

\footnotetext{
doc. $\mathrm{n}^{\circ}$ 47) junto con otras dos - dudosas- donaciones al monasterio silense, en el propio Santo Domingo en 1 de julio (Ibid, docs. ${ }^{\circ}$ s 48 y 49). 1135 parece, pues, el contexto apropiado para BA79.

- Debe tenerse en cuenta que la única copia hoy disponible es la del Becerro, pero de los datos suministrados por BERGANZA (Antigüedades de España, II, p. 62), quien vio la carta original, parece desprenderse que el Becerro introduce cambios sustanciales. Quizá el más importante es que la signatura de Ordoño Gudestioz iba acompañada de la expresión obtinente Lara, suprimida en el Becerro. Esta entrada, junto con la presencia de Sancha, esposa de dicho personaje, sugieren que la carta fue elaborada en un contexto local, quizás en la propia Lara o en Arlanza, cosa que explicaría también la presencia de un escribano Vincentius desconocido entre los escribas regios, pero que podría ser un monje de Arlanza (cfr. LuCAS, Las Cancillerías Reales, p. 126). Aunque desde Berganza se viene pensando que Ordoño Gudestioz pasó a ejercer el señorío de Lara en nombre del rey inmediatamente a la desnaturalización de Pedro González, parece más lógico relacionarlo con la actuación regia sobre la zona y la carta foral de 1135 , en la cual actuó como agente el propio Ordoño Gudestioz. Sobre el contexto político, ver ESCALONA MONGE, Julio, Transformaciones sociales y organización del espacio en el alfoz de Lara en la Alta Edad Media, Universidad Complutense, Tesis Doctoral Inédita, 1996. Como conclusión, proponemos corregir la fecha del documento BA79 de 1130 a 1135. Esto no supone un juico sobre su autenticidad, que parece dudosa en su forma actual. Sí debemos hacer constar, en cambio, que dada la disposición de las piezas en el bloque B del Becerro, pensamos que, fuese auténtico o falso, su inclusión en el mismo sólo pudo tener lugar entre los años 1135 y 1141 , fecha del siguiente diploma de la serie.

32 Como ya se dijo, BA95 pertenecía a los fondos de San Martín de Villaquirán y pasó al archivo de Arlanza con posterioridad a la donación de 1154.
}

Hispania, LXI/2, núm. 208 (2001) 449-474 
falso de Lara de $822^{33}$; según Menéndez Pidal era de letra de la segunda mitad del siglo XIII y según Serrano, de pleno siglo XIV ${ }^{34}$.

Por tanto, el Becerro parece haberse elaborado en cuatro fases principales:

- Bloque A: compuesto probablemente durante el reinado de Urraca o comienzos del de Alfonso VII, en que parece primar el orden temático y el desorden cronológico.

- Bloque B: compuesto a fines del reinado de Alfonso VII o -más probablemente - durante la minoría de Alfonso VIII, en que los textos se suceden casi en orden cronológico, en un espectro limitado al reinado de Alfonso VII.

- Bloque C: en que, de manera esporádica y escasamente selectiva, se fueron añadiendo otros textos.

- Adiciones finales: incorporación tardía de tres textos aprovechando espacios disponibles al comienzo y al final del códice.

La elaboración del Becerro como tal se limita a los dos primeros bloques; el tercero es una mera extensión, y el cuarto un simple goteo, cuando hacía ya mucho tiempo que el Becerro formaba parte de la Biblioteca de Arlanza. Dejando, por tanto, a un lado los dos últimos, centrémonos a continuación en los bloques A y B, los más relevantes para comprender el proceso de confección de la obra.

\section{Estructura interna del Bloque A}

La Figura 3 recoge la distribución de los documentos del bloque A, agrupados por su contenido, reflejando las agrupaciones cuándo se refieren a una misma zona o bloque de intereses del monasterio.

Figura 3. Bloque A: agrupaciones de documentos por su contenido.

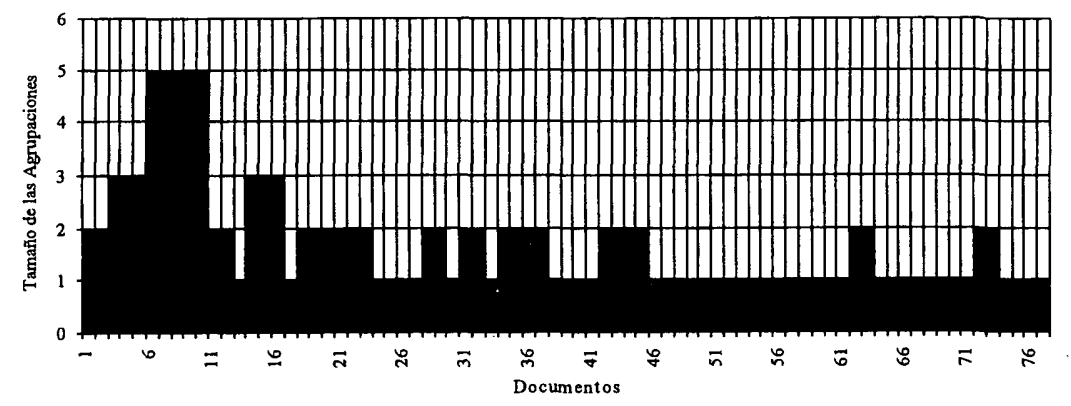

33 Sobre esta noticia y su contexto se tratará por extenso en la monografía citada en nota 7.

34 MenÉndez Pidal, La Leyenda de los Infantes de Lara, pp. 447-448; SERRANO, Cartulario de Arlanza, pp. 32, nota 11 .

Hispania, LXI/2, núm. 208 (2001) 449-474 
De la distribución de dataciones se deduce, como acabamos de ver, que el Becerro de Arlanza parece haber sido concebido y realizado hasta BA77 según un criterio no cronológico. Explorando este primer bloque según un criterio temático (Figura 3) se comprueban tres fenómenos:

1) Aparecen, efectivamente, agrupaciones que responden al contenido de los diplomas y no a su datación. Sin embargo, los bloques nunca alcanzan un gran tamaño ( 5 documentos en el caso extremo) por contraste, por ejemplo, con el Becerro de Cardeña, donde las series llegan a alcanzar 15 o más documentos consecutivos relativos a un mismo tema.

2) La agrupación tampoco es perfecta en todos los casos. El ejemplo más llamativo es el ya visto del monasterio de Santa Marina de Cela o de Cela Quesón, cuyo material - cuatro piezas - aparece dividido en un grupo (BA28 y 29) y dos piezas dispersas (BA52 y 65).

3) En general, da la impresión de que a medida que se avanza en este primer bloque del Becerro el desorden aumenta. Hasta BA35 las agrupaciones, aunque pequeñas, se suceden con cierta continuidad, pero a partir de aquí todo son documentos sueltos, con excepción de algunas parejas.

Por lo tanto, el análisis de los agrupamientos temáticos dentro del bloque A sugiere claramente dos sub-bloques diferenciados (uno en que predomina la ordenación temática, aunque en bloques pequeños, y otro en que el desorden es casi total), que pueden corresponder bien a dos etapas en la elaboración del Becerro, bien a dos fases en la organización del archivo monástico, o incluso a ambas razones a la vez. ¿Podemos precisar más? Para ello es necesario tomar en consideración la clasificación de los documentos según su otorgante (Figura 4).

Al hacerlo, se aprecia que hasta el $n^{\circ} 35$ hay un cierto equilibrio entre diplomas regios y particulares, con un ligero predominio de los primeros hasta el $\mathrm{n}^{\circ} 15$ aproximadamente y de los segundos hasta el 35. En cambio, a partir de ese punto la proporción de diplomas particulares aumenta de manera brusca y sostenida, mientras que la de diplomas regios lo hace a un ritmo muy inferior: sólo 6 piezas de un total de 42. Este patrón, si los diplomas guardasen un orden cronológico, podría a primera vista ser interpretado como un alto grado de favor regio en las primeras etapas y un predominio de donaciones particulares en lo sucesivo; pero al tratarse de una distribución en la que el orden cronológico brilla por su ausencia, parece más razonable interpretarla de la siguiente manera: hasta el $n^{\circ} 35$, la documentación es indistintamente regia o particular, y muestra un alto grado de agrupamiento temático. Parece claro que en este grupo, que ya podemos denominar sub-bloque A1 predomina un criterio organizativo de tipo geográfico. En cambio, desde el no 36 al 77, que llamaremos sub-bloque A2, las agrupaciones geográficas son pocas y de pequeña envergadura, mientras que parece predominar una organización según el otorgante. Pensamos que estas ideas resultan muy relevantes a la hora de considerar tanto el proceso de confección del Becerro como la organización del archivo arlantino. 
Figura 4. Becerro de Arlanza. Bloque A. Documentos seriados según el otorgante.

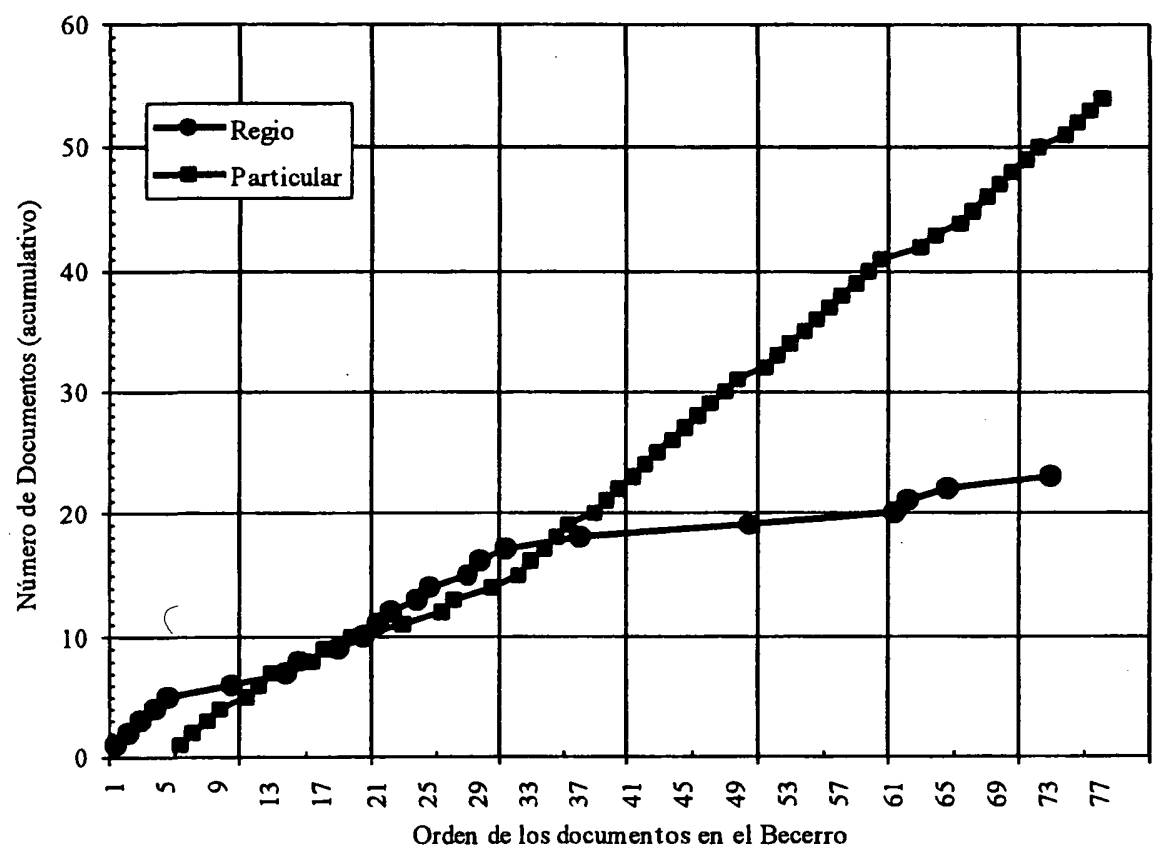

Estructura interna del Bloque B

En cuanto al Bloque B ( $\mathrm{n}^{\circ} \mathrm{s} 78$ a 92), una simple ojeada basta para cerciorarse de que el criterio que prima en él es el cronológico, pero en la Figura 5 se percibe claramente cómo los textos siguen una línea ascendente hasta BA88 (año 1155) y a partir de ese punto el desorden vuelve a reinar. Para comprender esta inflexión debemos tomar en consideración de nuevo los otorgantes de los documentos.

Desde BA78 a BA88 tenemos un total de once documentos, de los cuales todos menos tres son otorgados por el rey Alfonso VII (uno de ellos repetido). Los tres restantes corresponden a una donación efectuada por Rodrigo González de Lara y un conjunto de altísimos magnates castellanos (BA80), a una concordia entre Arlanza y la Iglesia de Osma (BA82), y a una donación del infante Sancho, futuro Sancho III (BA84). En todo caso, se trata de textos de gran relieve y el tercero se puede considerar regio. En cambio, a partir de BA89 tenemos otra donación por Sancho III aún en vida de Alfonso VII y tres documentos particulares sin orden cronológico ni temático alguno. Parece claro que la lógica interna del Bloque B consiste en copiar los documentos regios, por orden más o menos cronológico, y luego añadir - ahora de forma más anárquica- la documentación de origen privado. 
Figura 5. Becerro de Arlanza. Bloque B.

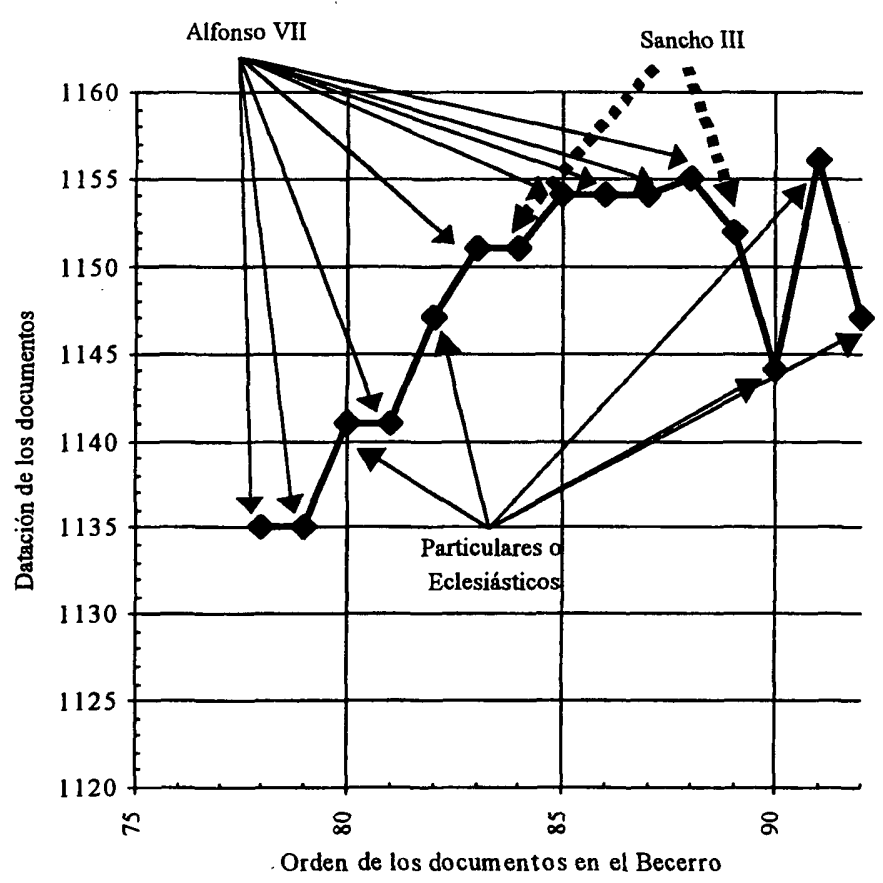

\section{LA ELABORACIÓN DEL BECERRO DE ARLANZA.}

Del estudio realizado se desprende que el Becerro de Arlanza es una obra compleja, elaborada en varias fases sucesivas. Se puede distinguir un total de cuatro bloques, de los cuales los dos primeros constituyen la composición del Becerro, propiamente dicha, y los dos segundos, sucesivas adiciones. Los bloques $A$ y $B$ pueden a su vez ser subdivididos en sub-bloques, de acuerdo con el criterio de ordenación de los documentos que contienen. Según esto, la estructura del becerro quedaría así:

- Bloque A: Redactado entre el reinado de Urraca y la minoría de Alfonso VII (circa 1109-1126). Comprende los documentos 1 a 77 del Becerro. Su ordenación interna es de carácter temático y no cronológico. Puede subdividirse, a su vez, en dos:

- Sub-bloque A 1: Documentos 1 a 35. Predomina la ordenación temática, aunque en agrupaciones pequeñas, de entre 2 y 5 piezas. Los otorgantes tienden a ser indistintamente regios o particulares, con ligero predominio de los primeros hasta el documento $15 \mathrm{y}$ de los segundos hasta el documento 35 . 
- Sub-bloque A 2: Documentos 36 a 77. El desorden es mucho más acusado. Apenas hay agrupaciones y cuando las hay son de parejas de diplomas. En cambio, la proporción de diplomas particulares aumenta de manera constante en todo el tramo.

- Bloque B: Redactado entre fines del reinado de Alfonso VII y la minoría de Alfonso VIII (el texto más moderno del becerro es de 1156 y ninguno de los documentos arlantinos posteriores a 1166 fueron copiados en el Becerro). Comprende los documentos 78 a 92 del Becerro. Su ordenación es de carácter preferentemente cronológico, aunque se pueden distinguir también dos subbloques:

- Sub-bloque B 1: Documentos 78 a 88. Se disponen en orden cronológico casi perfecto y se trata de diplomas otorgados por personas regias o muy próximas a su círculo (con excepción de un diploma eclesiástico).

- Sub-bloque B 2: Documentos 89 a 92. Se disponen sin orden cronológico ni temático. Coinciden en ser todos ellos pertenecientes al rango cronológico citado, pero sin contener ningún diploma regio.

- Bloque C: Redactado en torno al último cuarto del siglo XII. Comprende las piezas 93 a 97 . Se inicia con una noticia sin datación ni estructura diplomática e incluye un documento del siglo XII y dos del XI y una nueva noticia sin fecha. Se trata de meras adiciones, sin orden ni lógica interna.

- Adiciones finales: Como conjunto, no tiene fecha de redacción. Su formación pudo darse entre el primer tercio del siglo XIII y la primera mitad del XIV. Se trata de piezas incorporadas sin orden ni correlación, llenando los espacios disponibles en el códice: una noticia sin datación en el folio final y dos documentos copiados en el folio $1^{\circ}$ anverso.

\section{El PRoblema de los diplomas fundacionales de SAN PedRo de AR- LANZA.}

Pensamos que el análisis de interno del Becerro lleva a conclusiones relevantes para la debatida cuestión de la fundación de Arlanza. Como es sabido, son dos los diplomas que contienen dicho acto: SPA2 y SPA3, ambos fechados en 12 de enero de 912 y que fueron copiados en el Becerro con los números 1 y 2 respectivamente. El primero de ellos pretende ser otorgado por Fernán González y su esposa Sancha, mientras que el segundo lo es por la familia materna del conde: sus tíos maternos Gonzalo Téllez y Flámula, su madre Muniadona y su hermano Ramiro. Se trata de dos textos sumamente polémicos, que han dado lugar a un debate muy largo y cuya crítica no podemos abordar aquí en profundidad, aunque esperamos poder hacerlo de manera monográfica. Baste decir ahora que los últimos estudios tienden a negar la autenticidad de ambos, por diferentes razones. El más obvio es el caso del diploma de Fernán González, que es de un anacronismo aberrante. Pero también se discute la validez del 
dado por Gonzalo Téllez y otros parientes. Aunque no podemos extendernos sobre la cuestión aquí, pensamos que el texto de Fernán González es completamente falso, pero el de Gonzalo Téllez es válido en lo fundamental, aunque no está libre de interpolaciones que suponemos efectuadas en el momento de su traslado al Becerro.

Es importante recordar que las dos piezas formaron parte del archivo de Arlanza y que algunos autores modernos pudieron verlas, pero en la actualidad ambas están perdidas, quedando como testigos más próximos las copias del Becerro y una confirmación por Alfonso X del diploma de Fernán González. El dato es relevante, porque indica que Arlanza, aunque disponía de los dos textos, eligió para ser confirmado el otorgado por Fernán González (notoriamente falso) y luego lo utilizó en pleitos en que venía al caso ${ }^{35}$. En cambio, el diploma de Gonzalo Téllez nunca - que sepamos - fue presentado para su confirmación.

¿Es posible que el análisis del Becerro de Arlanza arroje alguna luz sobre esta espinosa cuestión? Pensamos que sí. Si se observa la estructura del Becerro, llama la atención que se inicie con dos documentos seguidos, los dos recogiendo la fundación del monasterio a cargo de diferentes personajes. BA1 es el de Fernán González (claramente falso) y BA2 el de Gonzalo Téllez (interpolado, pero con más visos de autenticidad). A primera vista, y a tenor de lo dicho más arriba, su inclusión en el sub-bloque A 1 implicaría que la falsificación de BA1 es anterior o coetánea a los años 1109-1126, pero creemos que se puede aventurar una hipótesis diferente, si bien algo más arriesgada.

Supongamos que, como es corriente en este tipo de códices, el Becerro disponía de un folio de guarda al comienzo (y probablemente también al final). Es un dato clave que los dos documentos del siglo XIII copiados en el folio 1, lo fueron, según Serrano, en el anverso y no en el reverso, como en principio sería más lógico esperar si hubieran aprovechado un folio de guarda. Si nuestra hipótesis es correcta, esto sería debido a que el reverso estaba ya ocupado por otro texto que se había insertado con anterioridad y que no sería otro que BA1. Por lo tanto, podemos reconstruir una secuencia muy diferente:

El Becerro original se iniciaba con la dotación fundacional de Arlanza por Gonzalo Téllez y su familia. Esta fase de redacción se produjo en torno a 11091126.

Para cuando se produjo la segunda fase de redacción del Becerro, el contexto político y cultural de Castilla era muy diferente, en pleno proceso de separación de León. Sabemos que por esta época estaba cobrando fuerza la leyenda de Fernán González, que hacía del primer conde unitario castellano el punto de referencia de las aspiraciones castellanas frente a León y Navarra. Hacia 1160, según la cronología más aceptada, la Crónica Najerense ya había incorporado una versión de esta leyenda, que siguió creciendo en lo sucesivo hasta convertirse en una pieza clave en la construcción histórica castellana con su inclusión en la Primera Crónica General de Alfonso X. Sabemos también que el monaste-

35 Ver, por ejemplo, AHN, Colección de Pergaminos, $n^{\circ} 205$.

Hispania, LXI/2, núm. 208 (2001) 449-474 
rio de Arlanza, que vivió su auge cultural y político entre los reinados de Alfonso VIII y Alfonso X, hizo grandes esfuerzos por conectarse con la leyenda de Fernán González y, así, también con las tradiciones fundacionales del ser político castellano. Esta aspiración culminó hacia 1250 con la redacción del Poema de Fernán González, donde la figura del conde ya aparece inseparablemente unida a la del monasterio, y donde está claramente formulada la leyenda de la fundación milagrosa de éste. No sólo eso. A la altura de mediados del siglo XIII, ya se había perdido la pista de la auténtica genealogía de Fernán González, para hacerle entroncar con los Jueces de Castilla, la otra gran leyenda fundacional castellana ${ }^{36}$. De la misma manera, entre ese momento y mediados del siglo XIV, también las tradiciones genealógicas de la zona de Lara fueron alteradas sustancialmente para incorporar a personajes del imaginario histórico comarcal - los Siete Infantes de Lara - a la genealogía de la familia Lara. Hay razones para sospechar que Arlanza fue uno de los principales talleres donde se llevaron a cabo dichas elaboraciones.

Este es el contexto en que cobra sentido nuestra hipótesis. En algún momento posterior $\longrightarrow$ muy próximo - a la muerte de Alfonso VII, se fue perfilando la idea de que el monasterio de Arlanza había sido fundado por Fernán González. Nada más adecuado que forjar un documento fundacional a la imagen del de Gonzalo Téllez, e incluso incorporando algún aspecto deseable como la absorción de Contreras por Arlanza. Ahora bien, a la hora de trasladar este texto al Becerro, el lugar idóneo para ello, era, por supuesto, el primer folio, pero éste estaba ocupado por la dotación de Gonzalo Téllez. En vista de eso, se optó por copiarlo en el reverso del folio de guarda, y es por eso que las adiciones posteriores tuvieron que utilizar el anverso.

No podemos, por desgracia, dar una fecha exacta para esta incorporación. La leyenda de Fernán González se desarrolló a lo largo de una etapa muy larga, y por tanto, pudo incluirse el diploma en cualquier momento entre 1135 (comienzo del bloque B) y 1255 (confirmación de la carta por Alfonso X). Sin embargo, no es probable que la leyenda estuviese formada tan pronto, y más bien hay que suponer que se añadió cuando ya estaba redactado el bloque $\mathrm{B}, \mathrm{o}$, quizá mejor, en pleno proceso de su elaboración, que, como dijimos, tuvo lugar en el agitado contexto de la minoría de Alfonso VIII. La coyuntura política y el contexto cultural encajarían perfectamente. A ello debe añadirse que, según un calco conservado en el monasterio de Silos ${ }^{37}$, el documento de Fernán González estaría escrito en letra visigótica alargada, lo que es lógico si fue hecho a imagen y semejanza del de Gonzalo Téllez, pero supone habilidades más verosímiles en el siglo XII que con posterioridad.

36 MARTIN, Georges: Les juges de Castille. Mentalités et discours historiqe dans lEspagne médiévale, París, 1992.

37 Desarrollamos esta cuestión con más detalle en Escalona, Julio; AzCARATE, Pilar; LARRAÑAGA, Miguel: «De la crítica diplomática a la ideología política; los documentos fundacionales de San Pedro de Arlanza y la construcción de una identidad para la Castilla medieval», VI Congreso Internacional de Historia de la Cultura Escrita, (Alcalá de Henares, 9-13 julio 2001), en prensa. 
En todo caso, si esta idea es correcta, encajaría a la perfección con la historia particular del Becerro de Arlanza, pero también iluminaría el complejo problema de la doble fundación del monasterio.

Pensamos que con estas páginas hemos llegado tan lejos como es posible sin inspeccionar directamente el Becerro. Aún así, y gracias a L. Serrano, es mucho lo que puede decirse sobre esta importante fuente. Las etapas de su redacción iluminan aspectos de la historia arlantina y dan pistas sustanciales sobre la forma en que se organizaban sus fondos archivísticos. ${ }^{38}$ También son relevantes en su contexto político: los dos bloques principales se redactaron en momentos turbulentos, y, sobre todo el segundo, refleja un peculiar «caldo de cultivo historiográfico». Ello además sugiere que el alcance de obras como el Becerro de Arlanza no se limita al ámbito administrativo o de gestión archivística, sino que constituyen auténticos alegatos políticos y de «pequeña historiografía» local. El Becerro de Arlanza, quizás sorprendentemente, muestra un alto grado de relación entre evolución política, construcción ideológica y compilación documental. ¿A qué género pertenecen los cartularios? ¿Para qué uso fueron concebidos? ¿Por qué acometer el esfuerzo de su confección en un momento concreto y no en otro? Estos interrogantes, y otros muchos relacionados con ellos, son materia de reflexión en el presente y lo serán para el futuro.

Somos plenamente conscientes de que buena parte de lo dicho tiene un carácter de hipótesis, cuando no de conjetura. Creemos sinceramente que las explicaciones que proponemos articulan de manera lógica y convincente los datos disponibles en este momento. En último término, este extremo sólo podría ser corroborado si el Becerro de Arlanza reapareciese y se pudiese analizar en profundidad, en especial en lo referente a las manos que intervinieron en su redacción. Las circunstancias de su sustracción hacen abrigar esperanzas de que no fuese destruido, por lo que sólo podemos terminar este trabajo deseando que las hipótesis que planteamos puedan algún día ser contrastadas con el original que, por desgracia, no hemos podido ver.

\section{AGRADECIMIENTOS}

Este trabajo ha sido realizado en el marco del proyecto Ref. 06/0106/1999 financiado por la Dirección General de Investigación de la Comunidad de Madrid y desarrollado por el Departamento de Historia Medieval del Instituto de Historia (CSIC) y el Departamento de Biblioteconomía y Documentación de la Universidad Carlos III de Madrid. Debemos agradecer a $\mathrm{D}^{\mathrm{a}}$ Mercedes No-

38 Como antes se dijo, en la actualidad trabajamos en la reedición de los fondos de Arlanza, y pensamos poder ofrecer una imagen más completa de su organización cuando ese trabajo culmine. 
viembre, Directora de la Biblioteca Zabálburu de Madrid, el habernos facilitado la consulta de los fondos y habernos proporcionado los datos disponibles sobre la historia del Becerro mientras formó parte de la colección. También queremos dar las gracias a las personas que han leído este trabajo y, con sus comentarios, nos han ayudado a perfeccionarlo, especialmente a la Dra. Isabel Alfonso, a la Dra. Cristina Jular y al Dr. Carlos Estepa. Y por supuesto, a Luciano Serrano, sin el cual —obviamente- este trabajo no hubiera sido posible.

\section{APÉNDICE: Tablas de concordancias entre las numeraciones del Becerro de Arlanza y las de la edición de Serrano}
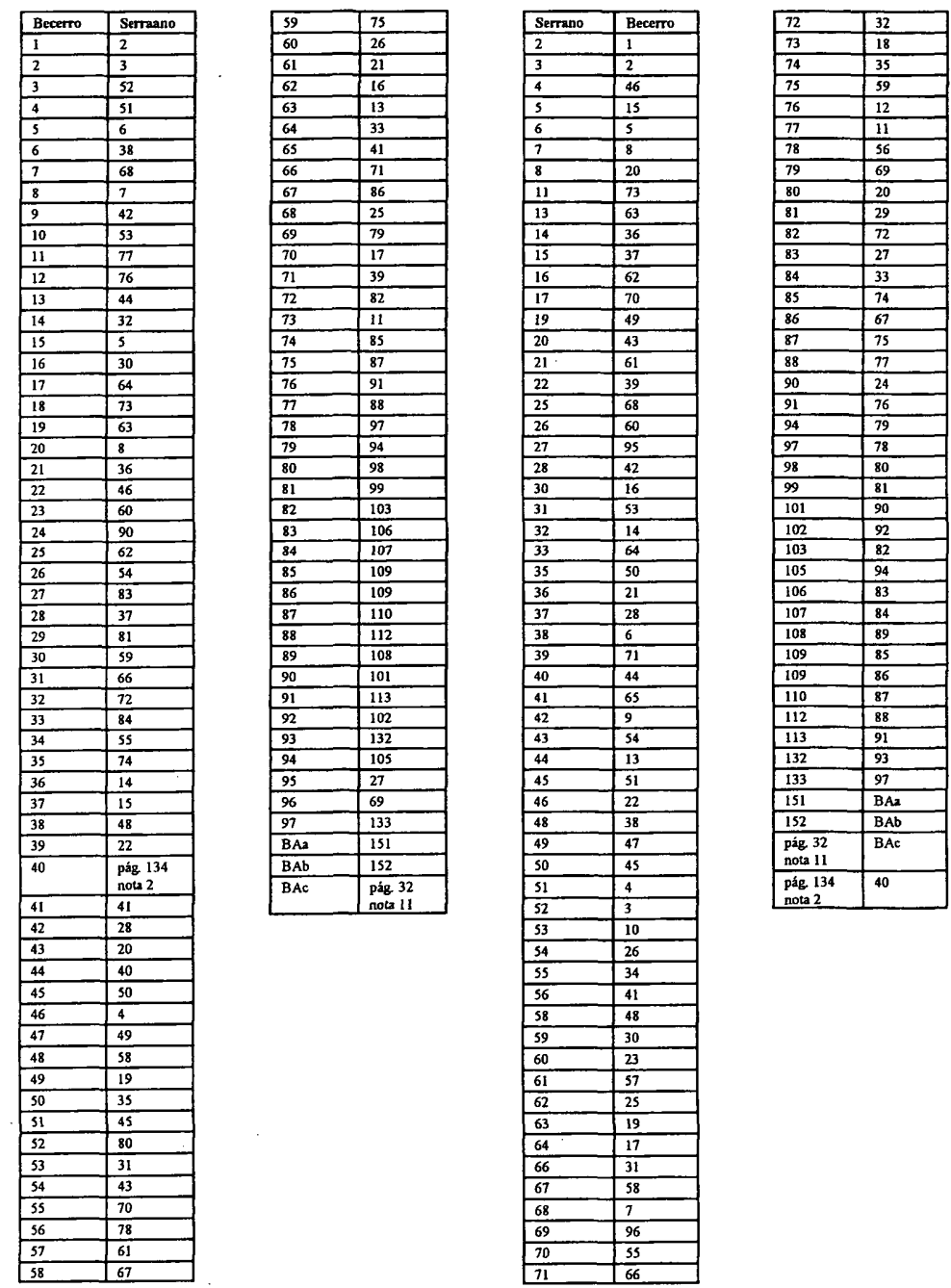